\title{
A PALAVRA FINAL É A DO MEU PROFESSOR DE DIREITO? reflexões pedagógicas a partir um ensino jurídico construtivista, entre um plano de aula opressor e libertador ${ }^{\mathrm{I}}$
}

\author{
Nick Smaylle da Luz Moreira ${ }^{2}$
}

RESUMO: O artigo acadêmico em questão é o resultado de estudos e reflexões sobre o Ensino Jurídico brasileiro e seus desdobramentos na formação do bacharel, bem como na formação docente do sujeito formador, a partir das pesquisas e debates evidenciados na PósGraduação Lato sensu em Docência no Ensino Superior da Pontifícia Universidade Católica do Rio Grande do Sul (PUCRS). O trabalho pretende incitar discussões não apenas sob o tema principal - ensino jurídico - mas também, acerca de seu histórico no Brasil, dissertando sobre a realidade das Faculdades de Direito, da docência universitária, dos elementos pedagógicos institucionais em Instituições de Ensino Superior, dos processos de ensino e aprendizagem, dos métodos de ensino de Direito e também, das demandas e problemáticas envolvendo esse tipo de ensino. Ao mesmo tempo que levanta demandas sob uma crise nessa ênfase do ensino superior, propõe soluções aplicadas estruturadas por meio de teorias e ideias, a fim de oferecer efetividade no ensino do Direito. Como aporte teórico foi utilizado a pesquisa bibliográfica, caracterizando-se de cunho qualitativo, com a utilização de métodos científicos: indutivo, dialético e histórico.

Palavras-Chave: Ensino Jurídico. Docência. Aprendizagem.

ABSTRACT: The academic article in question is the result of studies and reflections on Brazilian Legal Education and the unfolding in the formation of bachelor, as well as in the teacher training of the trainer subject, based on the research and debates evidenced in the Lato sensu Post-Graduation in Teaching in Higher Education of the Pontifical Catholic University of Rio Grande do Sul (PUCRS). This work intends to stimulate discussions not only under the main theme - legal education - but also, about history of the theme in Brazil, discussing the reality of the Faculties of Law, university teaching, institutional pedagogical elements in Higher Education Institutions, processes of teaching and learning, the methods and techniques of teaching Law and also of the demands and problems involving this type of teaching. At the same time that it raises demands under a crisis in legal education, it

\footnotetext{
${ }^{1}$ Este artigo foi realizado como Trabalho de Conclusão de Curso - TCC, da Pós-Graduação Lato sensu em Docência no Ensino Superior da Escola de Humanidades da Pontifícia Universidade Católica do Rio Grande do Sul (PUCRS). Por fim, cumpre ainda salientar que a artigo teve como orientadora, a Profa. Dra. Rosane Oliveira Duarte Zimmer.

${ }^{2}$ Advogado, Bacharel em Direito (Faculdade Mineira de Direito, PUC Minas, 2014), Especialista em Docência no Ensino Superior (Escola de Humanidades, PUC RS, 2018), pós-graduando em Direito Econômico e Regulatório (Instituto de Direito, PUC Rio). É membro do Grupo de Pesquisa "Filosofia, Religiosidade e suas interfaces" (PUC Minas/DGP-CNPq). ORCID: oooo-ooo3-2274-40ir Contato: smaylle.nick@gmail.com/nick_smaylle@hotmail.com.
} 
proposes solutions structured through theories and ideas, in order to offer effectiveness in the teaching of Law. As a theoretical contribution, bibliographical research was used, characterizing it in a qualitative way, using scientific methods: inductive, dialectical and historical.

KEY WORDS: Legal Teaching. Teaching. Learning.

\section{INTRODUÇÃO}

O questionamento que dá título a esse artigo foi feito, propositalmente, pensando nos acadêmicos das faculdades de Direito no Brasil, que aula após aula, encontram-se diante de docentes justificados pelo argumento de autoridade que o conhecimento da lei ou a consolidação acadêmica os proporciona, dessa forma, a ministrarem lições expositivas sem a consciência da frequente preparação pedagógica, tão necessária à prática escolar, contrapondo-se nesse sentido, a uma pedagogia relacional.

Nesta obra acadêmica, o tema principal será a dissertação em relação a aspectos do Ensino Jurídico, tal como, suas implicações, paradoxos e eventuais causas que se emergem especificamente nas graduações em Direito. As controversas e opiniões expostas dos métodos utilizados para ministração do conteúdo jurídico são crescentes, da mesma maneira que, a percepção sobre as poucas metodologias empregadas em sala de aula.

Este artigo buscou entender essa modalidade de ensino, suas complexidades e fatores históricos que transportaram o cenário jurídico acadêmico para uma pedagogia que se resume apenas ao uso da aula expositiva, com pouca utilização de tecnologia e inovação educacional, tendo a transmissão bancária do conteúdo alto valor em detrimento da aprendizagem significativa dos alunos.

Nessa lógica, o presente trabalho acadêmico pretendeu, além de conhecer e compreender as vertentes do ensino jurídico, contribuir também para as Ciências Jurídicas e da Educação, evidenciando a concepção de planos de aula que pudessem gerar, a partir de uma educação construtivista e ensino participativo, uma série de atributos e capacidades ${ }^{3}$ para aumentar a aprendizagem e autonomia dos alunos, além de proporcionar qualidade de ensino aos cursos de Direito.

Por essa via, o presente paper contextualizou elementos pedagógicos que se fazem necessários para o planejamento de aula nos cursos de graduação em Direito, principalmente do ponto de vista institucional.

Sob a seara metodológica, a pesquisa se caracterizou com uma abordagem qualitativa e natureza aplicada, tendo o trabalho procedimento técnico fundamentado na busca bibliográfica, ademais, com utilização dos métodos científicos de abordagem indutivo e dialético. E de procedimento, o histórico, baseando-se como suporte para análise de conteúdo, a hermenêutica dialética apresentada por João Batista Libânio:

\footnotetext{
${ }^{3}$ Entre os variados atributos e capacidades que o Plano de Aula poderia ter, cita-se como exemplo: novas metodologias de ensino do Direito, participação e autonomia do aluno na aula, planejamento escolar, do mesmo modo que, um novo discernimento aos docentes dos cursos jurídicos do Brasil, com o intuito de estimular um perfil apropriado para atuação pedagógica universitária, a manusear métodos de ensino de qualidade para o fomento de uma aprendizagem significativa. Ao longo do trabalho, serão expressas inferências a essa temática.
} 
[...] conserva o caráter absoluto da verdade metafísica clássica e o caráter interpretativo das filosofias da modernidade de tal maneira que há um processo hermenêutico em que as verdades, sem se negarem, são compreendidas em novas coordenadas. Todo conhecimento humano é interpretação, mas de uma realidade que tem sua objetividade independente do sujeito. É uma relação sujeito-objeto. A maneira humana de conhecer e interpretar. (LIBANIO, 200I, p. I88).

Foram analisadas publicações referentes ao tema (livros, artigos, teses, etc.), a legislação vigente, casos especiais divulgados pela imprensa digital, que auxiliaram no desenvolvimento do tema e na construção das ideias contidas na referente obra dissertativa.

\section{UM BREVE PROCESSO HISTÓRICO DO ENSINO DO DIREITO}

A caso observado a historicidade do ensino, de modo especial o do Direito, percebese as muitas explicações acerca de seu início, entretanto, de forma a apontar uma origem, verifica-se conforme Marchese (2006, p. 14) a seguinte conclusão: "Com o desenvolvimento dos povos e a aparição da arte de escrever, surge a lei escrita, e com isso sua interpretação, a necessidade de profissionais para conduzi-la e aplicá-la, e por decorrência, o ensino dessa atividade".

Assim sendo, em acordo com o autor retro citado, compreende-se que o ensino jurídico iniciou junto a necessidade de interpretação da lei, para o uso e aplicação na própria comunidade onde a estrutura de regras estava inserida. Já quanto ao motivo do ensino, naquele tempo histórico, informa-se um consenso na afirmação que se destinava a "preparação de pessoas capacitadas e conhecedoras das leis para preencherem cargos administrativos, desempenharem serviços junto à administração imperial e advogar em defesa de outrem perante qualquer tribunal" (ibid).

Conquanto, apesar do objetivo de formação, é um fato curioso destacar que a época, não existia professores para lecionar, uma vez que, as próprias pessoas da comunidade reuniam-se de forma avessa para aprender e compreender a lei, assim, "o Direito foi aprendido informalmente por aqueles que necessitavam de seu conhecimento para exercerem suas funções políticas e administrativas." (ibid).

Posteriormente, no que diz respeito ao surgimento do Direito em instituições de ensino, seguindo a linha histórica de raciocínio, é apropriado a firmar que iniciou na própria Roma antiga, mais propriamente nas escolas de retórica (ARANHA, 1995 apud ibid), onde os que aprendiam tal arte, questionavam acerca da junção desse ofício ao do conhecimento das instituições sociais e das leis, para assim, tendo como alvo a postulação desse conhecimento nos serviços públicos.

O esclarecimento dessa formação, pode ser compreendido sob a análise da própria história do curso no Brasil. Um fato singular a ser destaque, é que os profissionais da pátria que atuavam na área jurídica obtinham a formação no exterior, conforme Conceição expressa:

A primeira abordagem a ser feita, é que a Metrópole tinha o propósito de impedir a criação dos cursos superiores no Brasil. Isto aconteceu porque temiam que acabasse atingindo a Colônia, acarretando assim um processo de emancipação mais rápido. Neste primeiro momento do ensino jurídico, os estudantes de Direito viajavam do Brasil para estudar na Europa. Os movimentos para o surgimento do 
ensino jurídico no Brasil começaram obrigatoriamente pela Faculdade de Direito de Coimbra em Portugal. (CONCEIÇÃO, 2014, p. ıo).

Semelhante a citação, o contexto é confirmado por Machado (2006, p. I8) quando alude: "Antes, sem alternativas, os filhos das famílias abastadas eram mandados para Coimbra, Bolonha ou Paris para adquirirem conhecimento”. A partir dessa constatação, apenas os que possuíam recursos financeiros tinham a possibilidade de obter formação jurídica na Europa nesse sentido, deixando as margens do limbo educacional as camadas mais populares da sociedade. A especulação anterior coaduna com os registros de Conceição, advertindo que os formandos:

Representavam para os filhos da elite nacional um meio de se manter nas classes dominantes. No século XIX o que se procurava era a manutenção da ideologia dominante. Não havia uma preocupação de o aluno formar a sua concepção crítica sobre o assunto, mas sim perpetuar a ideologia dos pais. No início foi privilegiada a formação política em lugar da formação jurídica. (grifo nosso) (CONCEIÇÃO, 2014, p. II).

Por essa via, inicialmente contextualizada, repara-se que o Ensino Jurídico surgiu no Brasil num contexto de perpetuação da elite política, divergente da realidade encontrada no país a época, com tal característica, inexistia a formação para resolução dos conflitos sociais ou reflexões críticas do Direito em si, restringindo-se a mera instrução profissional para conservação futura do poder, acarretada dos cargos a serem ocupados.

Conforme o desenvolvimento do País, após um lapso histórico, foi necessário a criação de cursos da área, segundo destaca Rodrigues retirado de Machado (2006, p. I8) "os primeiros cursos de Direito no Brasil se instalaram em Olinda e São Paulo". Tal qual, a mesma autora ainda expressa que "O Brasil pôde deixar de mandar para o estrangeiro os jovens que queriam estudar Direito, formando aqui a elite que no futuro iria assumir o poder e ocupar os cargos públicos existentes." (MACHADO, 2006, p. 18).

O surgimento dos cursos jurídicos teve relação com a criação do Estado brasileiro, visto que, após a independência, houve a emancipação das instituições que antes, eram controladas por Portugal, como Marchese (2006, p. 47) exalta, “A criação e o surgimento dos cursos jurídicos no Brasil, estão intimamente relacionados às necessidades da real concretização do Estado Imperial Brasileiro, e vinculados às vontades e anseios das elites envolvidas no processo de independência.".

No decorrer do tempo, os cursos sofreram muitas alterações, em acordo com os processos histórico, jurídico e político de cada época, entretanto, com a inexistência de discussão acerca de um ensino crítico com estrutura pedagógica, como salienta Marchese (2006, p. 48):

Os debates, as longas discussões, e as exposições parlamentares do período deixam clara a total ausência de preocupação com o currículo e a finalidade de um curso de Direito. Em seu lugar, existe a grande preocupação de organizar uma estrutura de ensino que privilegie esse ou aquele programa ideológico e político. Prova disso, é que a única discussão pedagógica que se travou em torno da questão da composição do currículo, girou em torno da inclusão ou não do Direito Romano. 
Através desse viés, ainda atualmente no País, percebe-se a inalterabilidade do objetivo de formação do profissional na graduação em Direito, se observada as Diretrizes Curriculares dos Cursos de Direito do Ministério da Educação (MEC, 1994), que a partir dos eixos temáticos, continua a ser destinado a formação de bacharéis para o exercício da advocacia ${ }^{4}$, da mesma forma que, ocupação de cargos públicos nos poderes da república ou funções administrativas importantes no setor privado ${ }^{5}$. Resumindo-se, há um ensino estritamente técnico e profissionalizante, sem grandes debates acerca das ações pedagógicas e acadêmicas do curso.

Sob a afirmação anterior, examina-se a partir de uma contradição histórica, dado que, umas das preocupações no primeiro currículo do curso de Direito no Brasil, sob a ótica dos Estatutos ${ }^{6}$ criado por Luís José de Carvalho e Melo (Visconde da Cachoeira), era em relação a formação docente e práticas didáticas do professor no programa, como delineia Machado:

O grau de "Doutor" seria conferido apenas àqueles que atendessem aos requisitos especificados em estatutos próprios criados posteriormente. Somente quem obtivesse o título de doutor poderia ser escolhido para a função de lente, isto é, professor. Fica claro, assim, que a preocupação com a formação dos professores dos cursos de Direito nasceu junto com o próprio curso. (MACHADO, 2006, p. 20)

Da mesma forma, podemos verificar o mesmo entendimento quando Marchese expõe:

\begin{abstract}
Além dessa grande divergência, encontramos a preocupação do estatuto com a questão da metodologia e didática pedagógica defendidas pelo Visconde, que acreditava na forma especial e diferente para o ensino e explicitação de cada disciplina, apresentando programa e bibliografia a ser adotada, sendo que, o currículo aprovado com a lei sequer fazia menção a um critério pedagógico. (MARCHESE, 2006, p. 5i).
\end{abstract}

A vista disso, sob uma breve reflexão, entende-se que as ações educativas foram planejadas desde o primeiro momento histórico de criação do curso no Brasil, contudo, as Diretrizes Curriculares (MEC, 1994) atuais não fazem menção de aspectos que favoreçam o ensino ou a aprendizagem do conteúdo jurídico, citando apenas que as disciplinas da graduação devem estar em acordo com o Projeto Pedagógico da formação. Por esse ângulo, inexiste qualquer tipo de planejamento, segundo as Diretrizes, quanto a preparação pedagógica docente no curso ou aplicação metodologias de ensino como forma a fornecer qualidade as aulas, do ponto de vista legal.

\footnotetext{
4 Para que os Bacharéis em Direito estejam habilitados ao exercício da advocacia, é necessário preencher os requisitos do art. 8 da Lei federal no 8.906, de 4 de julho de 1994 (Estatuto da Advocacia da OAB), que é uma dentre tantas outras normas que o Advogado deve seguir, quando inscrito na Entidade;

5 Existe diversas opções de carreira para quem conclui o curso de Bacharelado em Direito, entre essas, visualiza-se as vagas mais bem assalariadas, incluído na carreia pública, que pelo fator histórico, ainda reserva boa parte de cargos políticos a serem ocupados pelos formandos da área (PIMENTA e KALLEO, 20I6);

${ }^{6}$ É prudente notar que, a criação dos Estatutos foi instituída por força do art. Io, da Lei de criação dos cursos jurídicos do Brasil (Lei de II de agosto de I827), que "regularia os cursos jurídicos naquilo em que fosse aplicável e que da lei não divergisse." (MARCHESE, 2006, p. 5o);
} 


\title{
3 OS LUGARES DO ENSINO E A IMPORTÂNCIA DO PLANEJAMENTO NA EDUCAÇÃO SUPERIOR
}

Por meio de uma clara constatação, entende-se o ato de planejar como indispensável em todas as fases e atos, sejam eles na vida, na profissão e demais esferas, não sendo diferente na docência. $\mathrm{Na}$ seara do ensino superior, que é a modalidade educativa desse trabalho acadêmico, é necessário ressaltar a relevância do "planejamento", frente ao compromisso do professor de prover uma educação de qualidade, pois, não há qualidade de ensino em aulas aplicadas sob o improviso, ou seja, sem a preparação para com os objetivos da aprendizagem.

Conforme o Glossário de Terminologia Curricular da UNESCO (2016, p. 72), o planejamento refere-se a "processo referente à tomada de decisões sobre o que, por que e como aprender, assim como sobre de que forma organizar o processo de ensino e aprendizagem, levando em conta exigências curriculares existentes e os recursos disponíveis. [...]”.

Pela mesma linha de argumentação, informam Batista e outros:

\begin{abstract}
A busca de uma sistematização efetiva das ações pedagógicas construídas no seio das instituições, contribuem com a consistência de um equilíbrio entre o processo de ensino e aprendizagem, enfatizando, aquilo que tenho e aonde quero chegar, quais os meus objetivos na construção das atividades diárias e se estas estão conectadas com a propostas de ensino do curso. (BATISTA, SOUZA e BATISTA, 2015, p. 3).
\end{abstract}

A partir da preocupação acima citada, compreende-se que planejamento é elemento para a criação de um equilíbrio entre os processos de ensino e aprendizagem junto aos objetivos educacionais. Isto posto, absorve-se dessa afirmação a tarefa árdua do professor e comunidade docente em encontrar ou conceber esse equilíbrio, por meio da organização curricular institucional.

Em uma perspectiva mais profunda, Paulo Freire aduz que planejamento vai além do equilíbrio, perpassando entre os objetivos educacionais e necessidades de mudança local:

Todo planejamento educacional, para qualquer sociedade, tem de responder às marcas e aos valores dessa sociedade. Só assim, é que pode funcionar o processo educativo, ora como força estabilizadora, ora como fator de mudança. Às vezes, preservando determinadas formas de cultura. Outras, interferindo no processo histórico instrumental. (FREIRE, 1986, p. 23).

O autor afirma a necessidade do ato de planejar estar atrelados a situações, utilidades e ocorrências da realidade local, sob pena de ser desconectado com a sociedade. O pensador idealiza e relaciona o ato de planejar com a mudança social, indo de encontro com algumas propostas $^{7}$ de cursos de Direito, que delineiam esses objetivos de modo curricular.

\footnotetext{
7 Algumas disciplinas de cursos de Direito no Brasil variam o conteúdo conforme a região do país onde se encontram, cita-se como exemplo a matéria de Direito Ambiental, muitas vezes sendo optativa, é incluída de forma curricular contendo legislações ambientais específicas dos Estados onde estão as Faculdades estão instaladas;
} 
O Ensino superior traz alguns traços específicos de planejamento, que se mostram evidentes para proporcionar uma aprendizagem de qualidade, questão que move toda a comunidade acadêmica da Instituição de Ensino, desde a sua fundação, até os destinatários finais nas salas de aula, que são os alunos.

\title{
3.I Ensino Superior: Definições e contextualização legal no Brasil
}

Também denominada como Educação superior, o Ensino superior percorreu diversas fases e modelos, em acordo com o regime político brasileiro vigente a cada época histórica e influência estrangeira, desde um ensino meramente profissional até uma aprendizagem científica, técnica ou recentemente a distância, como parte de uma educação democrática, atualmente disseminada. Traz esse nível de ensino uma aprendizagem de maior complexidade, de grau mais elevado, a partir de um sistema educacional próprio, o Glossário de Terminologia Curricular da UNESCO define-a:

\begin{abstract}
A educação superior baseia-se nos resultados do ensino médio, oferecendo atividades de aprendizagem em campos especializados da educação. Visa à aprendizagem em um alto nível de complexidade e especialização. Inclui o que é comumente compreendido como educação acadêmica, mas também inclui a educação tecnológica ou profissional avançada. (UNESCO-IBE, 2016, p. 45).
\end{abstract}

A partir desse entendimento, visualiza-se o ensino superior como um nível educativo que fornece uma aprendizagem específica, em determinada área do conhecimento humano. Sob autorização legal, esse nível de ensino se solidifica e torna-se real a partir de Instituições de Ensino Superior (IES), oferecendo cursos de nível técnico, nível superior tecnológico, bacharelado, licenciatura e sequenciais, além do mais comum, sendo as pós-graduações Lato e Stricto sensu, como também, demais ações que envolvam o tripé: ensino-pesquisaextensão.

Como já apontado, o ensino superior possui algumas peculiaridades que o diferem dos demais níveis de ensino, é importante frisar algumas finalidades que o mesmo possui, norteando e influenciando o âmbito educacional, dada pela Lei de Diretrizes e Bases da Educação Nacional (LDBEN), sendo:

\footnotetext{
I - estimular a criação cultural e o desenvolvimento do espírito científico e do pensamento reflexivo;

II - formar diplomados nas diferentes áreas de conhecimento, aptos para a inserção em setores profissionais [...];

III - incentivar o trabalho de pesquisa e investigação científica [...];

IV - promover a divulgação de conhecimentos culturais, científicos e técnicos que constituem patrimônio da humanidade [...];

$\mathrm{V}$ - suscitar o desejo permanente de aperfeiçoamento cultural e profissional [...];

VI - estimular o conhecimento dos problemas do mundo presente, em particular os nacionais e regionais, prestar serviços especializados à comunidade e estabelecer com esta uma relação de reciprocidade;

VII - promover a extensão, aberta à participação da população, visando à difusão das conquistas e benefícios [...] (Lei 9.394/96, art. 43).
}

A Lei de Diretrizes e Bases da Educação Nacional (LDBEN) n 9.394/96 exalta os principais propósitos do Ensino superior, definindo critérios, objetivos e parâmetros 
educacionais. Em relação as Instituições das quais oferecem a aprendizagem superior, essas não devem ser confundidas ou associadas diretamente com universidades, como é comum, pois, as IES são credenciadas de forma diversa e a partir de formatos organizacionais variados.

Diante das distinções, o Decreto 5.773/o6 no art. I2, evidencia no texto legal que: "As instituições de educação superior, de acordo com sua organização e respectivas prerrogativas acadêmicas, serão credenciadas como: I - faculdades; II - centros universitários; III universidades". A partir da referida legislação e sua simples citação por meio do artigo, é possível verificar as diferenças entre os centros acadêmicos, do mesmo modo que, perceber com o Decreto que a regulamentação do Ensino superior não se limita apenas a LDBEN, mas a todos os demais mandamentos legais que abordam o tema, nesse assunto, incluindo a Constituição Federal de 1988 em tópicos especiais ${ }^{8}$.

Ainda assim, cabe lembrar que para todo aparato educacional, é requisito indispensável vários tipos de planejamento afim de que a Instituição alcance excelência em relação a seus princípios e objetivos, como se verá no próximo subtítulo.

\subsection{Algumas vertentes do planejamento no Ensino Superior}

Ressaltado anteriormente, o planejamento tem papel fundamental no exercício de uma aprendizagem significativa e de qualidade no Ensino superior. O próprio termo auto se define enquanto sua importância, transformando a realidade numa direção escolhida. Nessa perspectiva, aludisse quanto a alguns exemplos institucionais de planejar, sendo: Planejamento Estratégico (PE); Planejamento de Desenvolvimento Institucional (PDI); Planejamento Pedagógico Institucional (PPI/PPP); Planejamento Pedagógico do Curso (PPC); Planejamento de Ensino/Disciplina (PD) e Planejamento de Aula (PA).

Esclarecendo o entendimento sobre alguns deles ${ }^{9}$, apresenta-se nesse momento o Planejamento Estratégico, comumente utilizado até por empresas privadas, tem um sentido de construção de identidade institucional. Se observado a questão conceitual, Oliveira citado por Ferreira e outros definem o PE como:

[...] uma metodologia gerencial que permite estabelecer a direção a ser seguida pela organização, visando o melhor grau de interação com o ambiente, considerando a capacitação da organização para este processo de adequação. (OLIVEIRA, I998 apud FERREIRA et al, 2006, p. 3).

Sendo assim, conclui-se que o Planejamento Estratégico tem por base um diagnóstico estratégico que permite dizer "quem eu sou enquanto instituição", "quais tendências no mercado", para aí definir, "para onde ir", no decorrer de 5 ou 7 anos, a partir de uma análise ambiental interna e externa. Diferente do Planejamento de Desenvolvimento Institucional - PDI, que, conforme Silva e outros:

\footnotetext{
${ }^{8}$ A Constituição da República Federativa do Brasil de 1988 fornece uma seção exclusiva para tratar do tema "Educação", qual seja, entre os arts. 205 a 214, fora os demais que tratam da matéria de forma complementar, espalhados ao longo texto constitucional;

${ }_{9}$ Neste capítulo do artigo, ressalta-se que será apresentado apenas alguns dos variados planos que possuem uma IES, com o intuito de compreender o objetivo principal de pesquisa desse trabalho acadêmico. Nota-se, não haverá um detalhamento complexo dos Projetos, mas uma sucinta citação e apresentação de cada plano;
} 
Tem como pressuposto o atendimento ao conjunto de normais vigentes, no que diz respeito à sua filosofia de trabalho, à missão a que se propõe a instituição, às diretrizes pedagógicas que orientam suas ações, à sua estrutura organizacional e às atividades acadêmicas que desenvolve e/ou que pretende desenvolver. (SILVA et al, 2014, p. 79)

A maioria dos planos institucionais, trazem consigo uma elaboração participativa, fomentado pela LDBEN, conforme o artigo I3: "I - participar da elaboração da proposta pedagógica do estabelecimento de ensino" e "II - elaborar e cumprir plano de trabalho, segundo a proposta pedagógica do estabelecimento de ensino" (BRASIL, 1996). Nesse sentido, visualiza-se a preocupação do legislador em fazer que com os Planos não sejam meros documentos produzidos para posteriormente serem arquivados, ou seja, registros burocráticos. Mas que isso, os Projetos, na complexidade da qual exige sua criação, vem como parte do processo de planejamento com o propósito de cumprir objetivos reais.

Agora, se atentado aos PPI, PPC e demais, estes possuem uma conotação mais delineada para a prática pedagógica da IES ou de determinado curso, apresentando princípios filosóficos e técnicos-metodológicos gerais que norteiam as ações pedagógicas e a organização didática da instituição/curso.

No exemplo a seguir, tem-se o Projeto Pedagógico do Curso, que é um instrumento de organização técnico-pedagógico-profissional, pois, elaborado de forma coletiva através do relacionamento com os demais planos da instituição, pretende proporcionar ao curso a excelência e organização, dada por meio de objetivos a serem cumpridos que propiciem a aprendizagem do destinatário final: o aluno.

Conforme o site Portal Educação, o PPC representa:

[...] o documento que orienta os docentes no planejamento da sua disciplina, de modo a concretizar a política educacional da instituição. Neste material didático optou-se por definir e denominar o documento como projeto pedagógico, entendendo que o aspecto político encontra-se expresso no ato pedagógico enquanto fazer educativo. (PORTAL DA EDUCAÇÃO, 2017).

Nesse segmento, têm-se um documento que agrega todos os componentes estratégicos, organizacionais e curriculares do curso, formado na maioria das vezes por: Apresentação; Histórico do Curso; Políticas Institucionais do Curso; Objetivos; Perfil do Egresso; Objetivos Curriculares; Estrutura Curricular; Metodologia; Estágio Curricular Supervisionado; Atividades Complementares; Processes de Avaliação; Infraestrutura de Apoio; Bases Legais e normativas, dentre outros ${ }^{\text {io }}$.

Indo pela mesma trajetória, sendo a etapa do planejamento que mais movimenta o aluno e o docente, lado a lado, no processo de ensino e aprendizagem, seria o Plano de Ensino/Disciplina e Plano de Aula, por vezes, confundidos no âmbito acadêmico, que apesar da semelhança e relação, possuem diferenças conceituais.

O primeiro, inclui uma previsão dos conteúdos que serão abordados ao longo da disciplina, é elaborado pelo professor responsável pela cadeira ou na ausência, algum

\footnotetext{
${ }^{10}$ Cabe indicar que a nomenclatura e o conteúdo no qual versa o Projeto Pedagógico varia de curso para curso e de Instituição para Instituição, conforme os objetivos propostos e contido em demais planos para cada estabelecimento de ensino superior;
} 
indicado pela Coordenação do Curso, que nem sempre, é o que ministra as aulas da matéria em específico. O Plano da Disciplina (PD) consiste num documento contendo algumas informações, como a emenda, os objetivos a serem alcançados pelo docente, o cronograma de execução das atividades, a bibliográfica necessária para leitura e compreensão da disciplina, dentre outros, entretanto, sempre relacionado ao Projeto Pedagógico do Curso.

Já o segundo, o Plano de Aula (PA), concebe-se como um delineamento do Plano de Ensino, levando os objetivos das matérias a serem cumpridos por meio de uma experiência didática concreta. O PA "sistematiza todos os conhecimentos, atividades e procedimentos que se pretende realizar numa determinada aula, tendo em vista o que se espera alcançar como objetivos junto aos alunos (LIBÂNEO, 1993).

Isso posto, percebe-se a importância de cada um para a Instituição de Ensino Superior, para o professor e para o aluno, uma vez que todos os planos estão interligados e fazem parte do processo de planejamento docente para o almejo de uma boa qualidade educativa.

\section{UM ENSINO JURÍDICO CONSTRUTIVISTA A PARTIR DE UM PLANO DE AULA LIBERTADOR}

Como já delineado pela história do ensino jurídico no primeiro capítulo deste trabalho, a falta de instrução ou consciência educacional sobre as didáticas no núcleo escolar sempre foi presente e até os dias de hoje, geram alguns pontos negativos. Nas Diretrizes Curriculares dos Cursos de Direito (MEC, 1994) existe uma lacuna no que diz respeito aos processos de ensino e aprendizagem, contudo, como prosperar no ensino jurídico evidenciando soluções em vez de demandas a partir das problemáticas aludidas?

Outro dilema presente nas Faculdades é em relação ao excesso de autoridade dada ao docente, que pelo alto prestígio de cargos em que ocupam, como o de desembargadores, juízes, promotores, delegados e demais no curso de Direito, descartam a necessidade de formação didática específica, pois por consciência do conhecimento das especialidades que possuem, em relação aos saberes da experiência/profissionais, veem como desnecessário o estudo de práticas pedagógicas no exercício da função docente. Desse modo, exaltando uma crise nesse sistema de ensino, conforme destaca o Instituto Brasileiro de Ciências Criminas:

\footnotetext{
Com uma visão essencialmente forense e uma abordagem meramente formalista do direito, a maioria dos professores limita-se a repassar sua experiência na magistratura, Ministério Público ou advocacia. Ou seja, há um desprezo à interdisciplinariedade e a uma formação de qualidade e uma valorização excessiva da dogmática jurídica, o que resulta num ecletismo teórico, na falta de rigor científico e num apego ao "princípio da autoridade doutrinária" alicerçado em autores anacrônicos e obsoletos. (IBCCRIM, 2008).
}

O resultado que a contextualização acima traz é o esclarecimento dos vícios que se instalam nesse determinado sistema de ensino, como exemplo: aulas expositivas mecanizadas e cansativas, ocasionando pouca aprendizagem do aluno em relação ao conteúdo, a grande reprovação nos Exames de Ordem ${ }^{\mathrm{II}}$, ou mesmo, a mercantilização do

(GIESELER, 2017), o mesmo faz destaque apenas ao último Exame, o XXIV, que segundo o Blog, teve maior índice de aprovações (GIESELER, 2018); 
ensino $^{12}$, dentre outros fatores gerados a partir da descrição de ensino que nesse trabalho, percebe-se atualmente como opressor.

Assemelha-se ao que Paulo Freire ensina a partir da consciência de concepção bancária de educação:

\begin{abstract}
A narração, de que o educador é o sujeito, conduz os educandos à memorização mecânica do conteúdo narrado. Mais ainda, a narração os transforma em “vasilhas”, em recipientes a serem "enchidos” pelo educador. Quanto mais vá "enchendo" os recipientes com seus "depósitos”, tanto melhor educador será. Quanto mais se deixem docilmente "encher”, tanto melhores educandos serão. Desta maneira, a educação se torna um ato de depositar, em que os educandos são os depositários e o educador, o depositante. (FREIRE, 2017, p. 8o).
\end{abstract}

A partir dos pensamentos, fatos e dados, extrai-se a consciência de como transformar a realidade opressora acima descrita no núcleo de cursos de Direito? Sendo ainda mais específico, indaga-se como remodelar o ensino jurídico para uma formação que vá de encontro aos anseios sociais e não para a perpetuação da elite política do país?

Então, a fim de encontrar soluções ao caso exposto, este artigo põe a prova o ensino construtivista como um dos caminhos viáveis, tal qual, de modo a superar o tradicionalismo constante parte de uma educação jurídica estagnada, libertando docentes e aprendizes para uma nova realidade educativa.

\title{
4.I A Teoria Construtivista: um ponto de vista diversificado
}

Um ensino construtivista vem à tona por meio da teoria construtivista, ou mesmo, do construtivismo, termo que segundo informa Sanchis e Mahfoud (2010, p. 19), "designa um conjunto teórico e de práticas que abrange a obra de muitos autores e desdobramentos práticos diversificados". Da mesma forma, o autor Coll retirado de Chakur (2014, p. I7) concorda que a teoria é pluralizada quando expressa que "pelo menos no âmbito da educação, é ilusório e falso falar do construtivismo no singular".

Assim definido, conforme Jean Piaget (1896-1980), um dos principais autores a destacar o pensamento construtivista, que embora não fosse pedagogo, mas biólogo, contribuiu de forma significativa ao campo da educação, uma vez que, suas pesquisas iniciais ${ }^{13}$ eram sobre as formas de aquisição do conhecimento, sendo que o compreendia da seguinte maneira:

[...] não pode ser concebido como algo predeterminado nem nas estruturas internas ${ }^{1}$ É possível perceber uma grande reprovação nos Exames de Ordem da $\mathrm{OAB}$ a partir dos dados evidenciados: Em 2016, a FGV Projetos - Núcleo

\footnotetext{
${ }^{12}$ A mercantilização do ensino cria algumas consequências educacionais como a visualização do aluno como cliente e o conhecimento como mercadoria, trazendo posicionamentos como o da OAB Seção Paraná, qual realizou uma moção de suspensão de novos cursos de direito por o anos (MIGALHAS, 2017), devido ao nível de qualidade dos cursos abaixo do esperado e a falta de mercado de trabalho para absorver o número de profissionais;

${ }^{13}$ As pesquisas iniciais de Jean Piaget surgiram a partir de uma teoria chamada "Epistemologia Genética", na qual "[...] é essencialmente baseada na inteligência e na construção do conhecimento e visa responder à questão não só de como os indivíduos, sozinhos ou em conjunto, constroem conhecimentos, mas também por quais processos e por que etapas eles conseguem fazer isso" (ABREU et al. 2010, p. 362);
} 
de Concursos, entidade que é responsável pelo Exame, junto ao Conselho Federal da Ordem dos Advogados do Brasil, atesta que entre os Exames II a XVII, apenas $56 \%$ dos examinandos foram aprovados (FGV Projetos Núcleo de Concursos, 2016). De tal forma, o Blog Exame de Ordem, coordenado pelo Advogado Maurício Gieseler, que realizada um acompanhamento das provas, reafirma o nível de dificuldade dos testes quando fornece alguns dados, como o do Exame XXIII, onde a reprovação chegou a $82,93 \%$ dos inscritos do sujeito, porquanto estas resultam de uma construção efetiva e contínua, nem nas características preexistentes do objeto, uma vez que elas só são conhecidas graças á mediação necessária dessas estruturas, e que essas, ao enquadrá-las, enriquecem-nas. (PIAGET, 2007, p. г apud NIEMANN \& BRANDOLI, 2012, p. 2).

Nessa perspectiva, sendo mais claro, em acordo com a descrição acima descrita, a aprendizagem é o resultado da relação do meio com o indivíduo e também, das estruturas que o próprio sujeito cria com o objeto de estudo. É como Becker (1992, p. 88) situa: "O sujeito age sobre o objeto, assimilando-o: essa ação assimiladora transforma o objeto". Sob esse entendimento, o sujeito constrói sua aprendizagem pelo toque e ação junto ao "objeto", que nessa citação, entende-se como o "conhecimento".

$\mathrm{Na}$ mesma linha de raciocínio, os autores Sanchis e Mahfoud (2010, p. 2I) destacam "Um construtivismo em que gênese/estrutura e sujeito/objeto se relacionam permanentemente.", e, num outro ponto, os mesmos pensadores completam: "Essa construção só é possível através de uma interação, mediada pela ação do sujeito, em que dois conceitos são centrais: a assimilação e a acomodação." (SANCHIS, MAHFOUD, 2oio, p. 2I).

Dessa forma, a teoria vem definindo a construção do conhecimento numa relação contínua de sujeito - objeto (conhecimento), como Carretero e Limón retirado de Chakur (2014, p. 18) aludem que:

[...] as diferentes posições que se consideram construtivistas têm em comum a ideia de que o conhecimento humano é produto da interação entre fatores internos e externos e se constrói "mediante atribuição de significado à informação enfrentada. (grifo nosso) (CARRETERO e LIMÓN, 1998, p. 173 apud CHAKUR, 2014, p. 18).

Apesar da pluralidade ${ }^{14}$ do termo a partir dos variados significados do construtivismo, o mesmo se resume a uma forma de construção, como Becker nesse momento, exalta:

Construtivismo significa isto: a idéia de que nada, a rigor, está pronto, acabado, e de que, especificamente, o conhecimento não é dado, em nenhuma instância, como algo terminado. Ele se constitui pela interação do Indivíduo com o meio físico e social, com o simbolismo humano, com o mundo das relações sociais; e se constitui por força de sua ação e não por qualquer dotação prévia, na bagagem hereditária ou no meio, de tal modo que podemos afirmar que antes da ação não há psiquismo nem consciência e, muito menos, pensamento. (BECKER, 1992, p. 88).

\footnotetext{
${ }^{14}$ Por esta compreensão, com um termo e teoria sob diversos ângulos, este artigo abordará a construção a partir de uma série de autores, tentando relacionar tal conteúdo ao que se vê de ideal e apropriado para um ensino jurídico de qualidade, restringindo o tema ao essencial para o alcance do objetivo final proposto;
} 
Sendo o completo oposto do ambiente empirista ${ }^{15}$ instalado nos cursos de Direito, e assim, por meio dessa construção contextualizada, não passiva ou receptiva do objeto, mas pelo agir e manuseio do mesmo, remetendo objetos enquanto conhecimento e sujeito enquanto educando, que nessa interação surge o aprender, validando nesse sentindo a teoria construtivista, como processo de aprendizagem significativa, sendo tema de estudos interdisciplinares, como de fato ocorre nesse paper acadêmico.

\subsection{A aplicação da teoria construtivista no ensino jurídico contemporâneo}

Entretanto, do que adiantaria a teoria sem a prática, assim, perfazendo-se necessário exemplificar o modo de aplicação ou criação de um ambiente construtivista, tal como e com qual impacto, se aplicaria numa educação como a jurídica, que é tradicionalista ${ }^{16}$ por natureza histórica. Haveria resistência? Como Argento (sem data, p. 12) indaga: "qual o resultado que será obtido por um professor cuja concepção do conhecimento for empirista ao utilizar um "ambiente construtivista" ou sua recíproca [...]".

A mesma autora ainda enfatiza que:

Outro aspecto primordial nas teorias construtivistas, é a quebra de paradigmas que os conceitos de Piaget trazem, é a troca do repasse da informação para a busca da formação do aluno; é a nova ordem revolucionária que retira o poder e autoridade do mestre transformando-o de todo poderoso detentor do saber para um "educador - educando", segundo as palavras de Paulo Freire, e esta visão deve permear todo um "ambiente construtivista". (ibid).

Dessa forma, a teoria construtivista vem para quebrar as barreiras impostas pela tradição, num sentido de abertura a mudanças efetivas ao espaço escolar que resultem num ambiente moderno e que dê suporte a subsídios que favoreçam processos de ensino e aprendizagem reais.

Apesar de Argento expressar a aplicação do construtivismo como "revolução", Becker torna a luz uma preocupante observação que:

[...] uma simples mudança de concepção epistemológica não garante, necessariamente, uma mudança de concepção pedagógica ou de prática escolar, mas sem essa mudança de concepção-superando o empirismo e o apriorismocertamente não haverá mudança profunda na teoria e na prática de sala de aula. A superação do apriorismo e, sobretudo, do empirismo é condição necessária, embora não suficiente, de avanços apreciáveis e duradouros na prática docente. (BECKER, 1992, p. 92).

Levantando a citação acima o questionamento, que somente a ciência da teoria e sua aplicação não geraria por si só os resultados que a mesma propõe na aprendizagem. $\mathrm{O}$ interessante para essa indagação é que, o próprio autor fornece a solução, quando diz "que o

\footnotetext{
is $\mathrm{Na}$ Teoria Empirista, segundo Becker (2008, p. 46), “o professor considera que seu aluno é tabua rasa não somente quando ele nasceu com ser humano, mas frente a cada novo conteúdo estocado em sua grade curricular, ou nas gavetas de sua disciplina. A atitude nós a conhecemos. $O$ alfabetizador considera que seu aluno nada sabe em termos de leitura e escrita e ele tem que ensinar tudo";

${ }^{16}$ Quando menciono o termo "tradicionalista”, quero dizer relacionado a educação seguindo a teoria empirista, que é expressiva no atual ensino jurídico. Cf Nota I4;
} 
movimento próprio do processo de construção do conhecimento deve impregnar a sala de aula, em particular, e o sistema educacional, em geral", completando, ainda, noutro trecho de sua obra que "O compromisso da Escola deve ser o de construir o novo, superando o arcaico, e não o de repetir, interminavelmente, o antigo." (ibid, p. 92).

Sob uma visão prática, associar um ambiente construtivista ao núcleo de uma Faculdade de Direito, conforme o desejo do autor retratado, estar-se-ia criando novos conteúdos, superando antigas estruturas didáticas de exposição, deixando de lado conteúdos obsoletos e criando um processo de construção do conhecimento a luz da realidade jurídica contemporânea e suas vertentes, tal como as problemáticas atuais.

Um outro ponto necessário à discussão, que talvez, poderia até ser um adicional ou parte dos processos de ensino, para a aplicação e execução de um ambiente que seja construtivista por natureza, seria a sugestão ao manuseio das Tecnologias de Informação e Comunicação (TICs) em sala de aula, não só de forma expositiva, como slides ou utilização de seminários com data show utilizados pelo professor, mas algo tecnológico em que o próprio aluno toque, crie e compartilhe. Por conseguinte, refletindo o que já foi delineado acima, a interação com o objeto.

Num exemplo do uso dessas tecnologias, Mercado (2016, p. 264) cita a utilização de TICs no ensino jurídico como preposto de interação, de mediação pedagógica, de produção de conhecimento colaborativo, de desenvolvimento de competências e autoria de conteúdos. $\mathrm{O}$ autor retro mencionado ainda reforça que "Novas formas de aprender e interagir com TIC exigem novas metodologias de ensino nos cursos superiores, especificamente nos cursos jurídicos" de forma "a provocar uma postura mais dinâmica e crítica dos acadêmicos, com a utilização de novas ferramentas de ensino, que podem contribuir para a implementação de um processo de ensino-aprendizagem emancipatório" (ibid).

Assim sendo, Mercado dá importância a emancipação, assemelhando-se a um processo de autonomia, criada a partir do uso adequado das TICs em sala de aula, fornecendo, sob esse viés, um ensino jurídico diferenciado, do preposto na atual realidade educacional. Nesse sentido, visualiza-se que as TICs são objetos de fomento à revolução do qual Argento (sem data) cita ${ }^{17}$, sendo tecnologias inovadoras de transformação do conhecimento tradicional e arcaico ao passo do novo, da criatividade e de novos saberes confeccionados.

A sobre-elevação da passividade e da opressão, para o surgimento da autonomia, é parte de uma competência que deve ser criada em detrimento da própria profissão do ensino em referência, que exige independência, no exercício da advocacia ${ }^{18}$. No caso do tema em tela, muitos alunos são tímidos, não se expressam de maneira clara, muito menos, exercendo o direito a voz, isso, quando há a oportunidade de falas à opinião autoritária do docente.

$\mathrm{Na}$ obra de Freire (2017, p. I07-I19), o autor contribuí para os processos de aprendizagem quando reforça o exercício do democrático debate por meio da educação problematizadora, que torna o educador uma espécie de educador-educando, educador humanista ou revolucionário autêntico, que é quando o mesmo valoriza o diálogo como parte da comunicação com os discentes, mas de maneira conquistada e realizada através da

\footnotetext{
${ }^{17}$ A autora Argento (sem data, p. 12) trata dessa questão quando cita "nova ordem revolucionária", que se instala em ambientes construtivistas. Cf. p. I5;

${ }^{18} \mathrm{O}$ exercício da advocacia é considerado uma profissão autônoma e liberal, exigindo independência conforme o art. $7^{\circ}$, inciso I e § $2^{\circ}$, além do art. I8 do Estatuto da Advocacia (BRASIL, 1994);
} 
confiança (como premissa de companheirismo), do amor pelo mundo (como ato de coragem e valentia), por fim, da fé nos homens, da esperança e da solidariedade entre eles.

$\mathrm{O}$ autor remete mais uma vez esse pensamento quando expressa que: "Ao fundar-se no amor, na humildade, na fé nos homens, o diálogo se faz uma relação horizontal, em que a confiança, de um polo no outro é consequência óbvia." (grifo nosso) (FREIRE, 2017, p. II3). Nesse quesito, visualiza-se nesses ideais uma postura dialógica de docência, ponto que acrescentaria transparência e veracidade a aulas de Direito construtivistas.

A partir do estudo, engenho e compromisso, enxergando à docência como "arte construída”, é possível conceber vários métodos de ensino que podem ser utilizados pelo professor para o fomento de um ambiente construtivista, além dos já citados acima. São alguns como: rodas de conversa, contrato didático, juris simulados, estudos de cases ou a partir de projetos elaborados conjuntamente, diários de aula, mapas conceituais, dentre outros disseminados e aplicados em Instituições de Ensino Superior.

Todavia, como já exaltado no segundo capítulo desta obra, é necessário certo planejamento técnico para a execução desses pensamentos, práticas e ideias, com um tipo de organização próximo ao docente, de modo que o próprio professor participe ativamente também do processo, pois, do que adiantaria a aplicação de aulas jurídicas construtivistas, com a aplicação de TICs e demais métodos a partir do improviso? Sobre essa adversidade, existe o Plano de Aula, como será abordado no subcapítulo a seguir.

\subsection{O ensino jurídico construtivista efetivado a partir de planos de aula}

O Plano de Aula (PA) é uma ferramenta antiga usada por professores, todavia, muitas vezes confundida com o Plano da própria disciplina (PD), que envolve neste aspecto, o conteúdo inteiro da matéria, como a descrição do conteúdo, material, tecnologias utilizadas e obras a serem lidas, que em geral, é confeccionada junto aos professores titulares da disciplina e a coordenação do curso superior.

O PA, como já demonstrado nesse paper, seria o detalhamento do Plano da Disciplina e em acordo com o Projeto Pedagógico do Curso, algo que o professor possa utilizar como um manual de aula, para não se perder ou se distanciar do conteúdo, um modelo de organização técnica autoral elaborado pelo próprio docente, podendo ser, em acordo com os objetos traçados e dissertados nesse trabalho, instrumento para revolução, se, realizado/confeccionado/planejado para um ensino jurídico construtivista.

Sob uma clara constatação, é certo que muitos docentes, acostumados a ministrar o mesmo conteúdo da disciplina todos os semestres, nem elaboram PAs, utilizando-se apenas dos PDs com método de ensino expositivo sob o improviso para ministração das aulas ${ }^{19}$. Nesse ponto, ressalta-se a importância de vislumbrar o PA como um divisor de águas, sendo uma espécie de arquitetura pedagógica que se colocado em ação, do ponto de vista técnico, feito para um ensino jurídico construtivista, proporcionaria libertação, emancipação e autonomia dos alunos, favorecendo os processos educacionais, na figura de uma aprendizagem crítica.

\footnotetext{
I9 Utilizando-se de exemplo para tal afirmação, a percepção que o autor deste artigo tinha na própria formação jurídica, quando assistia aulas visualizando improvisação pelo docente, ou quando o professor, evidenciava para a turma a utilização apenas do Plano de Ensino como guia de ministração;
} 
Por esse ângulo, os PAs poderiam ser uma espécie de voz docente, se percebido o que Paulo Freire (2017, p. 108) expõe: "Não é no silêncio que os homens se fazem, mas na palavra, no trabalho, na ação-reflexão" (grifo nosso). E é nessa ação-reflexão do qual o autor menciona, que o PA poderá ser constituído, por que vale ressaltar também, que, essa modalidade de Plano é a própria "ação". Todavia, não pode ser desvinculado da "reflexão", no sentindo de que o docente não pode criar um plano de aula do qual considera perfeito a jus do ensino jurídico construtivista e utiliza-lo infinitamente, sob pena de o tornar obsoleto ao tempo e ao próprio significado de mudança exacerbado e a necessidade de transformação das didáticas educacionais já delineadas nesse trabalho (como a aula expositiva).

Consoante demonstra Libâneo (1994, p. 222) retirado de Dorta, Franco (2013, p. 491), expressa que: "A ação de planejar, portanto, não se reduz ao simples preenchimento de formulários para controle administrativo, é, antes, a atividade consciente da previsão das ações político - pedagógicas”. Assim, reafirmando o autor a necessidade de reflexão docente sobre a prática pedagógica, que inclui nessa ação, a constituição de um Plano de Aula nos parâmetros abordados acima.

\section{CONSIDERAÇÕES FINAIS}

A caso feito uma observação criteriosa do artigo, visualizar-se-á, inicialmente, que o mesmo tenta além de mostrar o histórico do ensino jurídico, evidenciar também os planos e projetos que uma Instituição de Ensino Superior deveria ter. O mesmo trabalho aborda a crise no sistema de ensino em questão, uniformemente tentar fornecer uma reflexão, a partir de práticas docentes que ressaltem novos métodos de ensinar Direito.

No histórico do ensino jurídico no Brasil, desde sua fundação, foi a de conceber profissionais para composição da elite política do país, uma realidade presente até nos dias que correm. Entretanto, a pergunta mais composta continuou sendo é a de como transformar esse fato? Se no momento atual, é comum que os formandos continuem a almejar altos cargos com a graduação, com intuito pessoal, financeiro, político e não social.

O cerne do problema, conforme delineado ao longo do trabalho, vai primeiro, desde o planejamento político do curso, por meio das Diretrizes Curriculares do Curso (MEC, 1994), até o institucional, que reflete no Projeto Pedagógico do Curso ou Plano de Ensino da IES. Já que no primeiro documento, resta claro observar que não contempla ações pedagógicas específicas que careceria ao curso, quando na verdade, a declaração retrata apenas aspectos teóricos das matérias, além dos procedimentos administrativos de praxe. A transformação nos moldes mencionados, do documento verificado acima, é o primeiro passo para mudança das ações pedagógicas.

Outra indagação a ser exaltada é: O que falta para a conscientização que os processos de ensino e aprendizagem sejam visualizados como fator importante, quando não, determinante na qualidade dos cursos e aprendizado do destinatário final? Pois, o oprimido aluno, que por muitas vezes sofre assistindo apenas a aulas expositivas, não possui qualquer consciência dessa opressão, que acata como uma ordem, aulas sem qualquer fundamento epistemológico e pedagógico ou com diferentes variáveis de visualizar o conhecimento.

E quanto ao professor? Revestido de argumento de autoridade, dado através do cargo que ocupa fora da universidade ou da alta titulação acadêmica que possui sendo professor de cadeira, ainda sim, é desprovido de técnicas e métodos de ensino que subsidiem o acadêmico a pensar criticamente e de forma comunitária, porém uma isenção inconsciente, já que não 
possui capacitação pedagógica que o faça refletir sobre seus métodos de ensinar. Percebe-se raro uma IES que forneça cursos de capacitação nessa área, e ainda mais raro, professores de direito tornarem-se lúcidos de participar dessas formações. A capacitação do docente seria o segundo passo para transformação do ensino. É importante ressaltar que mestrado e doutorado não faz do pesquisador um educador, mas um especialista numa determinada área do conhecimento humano.

Sob a obra em referência, a mesma tentou viabilizar a mudança do ponto de vista institucional, principalmente por meio de uma referência que fosse mais próxima da realidade educacional, que é o Plano de Aula. Faz-se mister que este trabalho não dissertou sobre um plano de aula comum, mas delineado através de um ensino que fosse construtivista por natureza, tornando conscientes professores e comunidade acadêmica da necessidade de transformação das didáticas. Na teoria construtivista, que é uma dentre as variadas teorias que podem ser utilizadas pelos professores, não existe palavra autoritária, não existe relação de subordinação ou obediência, não existe posições hierárquicas ou palavras e argumentos finais.

Em aulas de Direito, são dois polos da relação oprimidos e inconscientes de seus papeis em sala de aula, aluno e professor, que conforme a exposição de motivos traçados nesse paper, espera-se a partir da reflexão e tomada de consciência, criarem juntos um ambiente escolar permeado de aprendizagens significativas, ensinando e aprendendo lado a lado, através de metodologias ativas de ensino e aprendizagem construtivistas, despertadas através do conhecimento pedagógico docente.

Por fim, ressalta-se que o autor desse artigo realizou a especialização em docência a partir da ciência e consciência da necessidade de aptidão de saberes pedagógicos para ministração de aulas de qualidade. Buscando o mesmo não só contribuir para a sua área de formação, que é o Direito, mas também, conforme a própria abordagem meramente formalista (IBCCRIM, 2008) que a esfera jurídica possui, demonstrar as possibilidades que os processos de ensino e aprendizagem revelam, por meio do plano de aula, confeccionado através de um ensino jurídico construtivista, deixando de lado o tradicionalismo constante, explicitando que a palavra final dada, num contexto acadêmico, nem sempre é a do professor de direito, quando na verdade, após a reflexão de consciência e dos saberes pedagógicos, deveria haver uma palavra final em sala de aula?

\section{REFERÊNCIAS}

ABREU, Luiz Carlos de et al. A EPISTEMOLOGIA GENÉtiCA DE PIAGET E O CONSTRUTIVISMO. Rev Bras Crescimento Desenvolvimento Hum. 20I0. Disponível em 〈http://pepsic.bvsalud.org/pdf/rbcdh/v2on2/I8.pdf 〉. Acesso em I4 de março de 20I8;

ARGENTO, Heloisa Teixeira. TEORIA CONSTRUTIVISTA. Disponível em $\langle$ http://www.robertexto.com/archivo5/teoria_construtivista.htm〉. Acesso em 27 de março de 2018;

BATISTA, Aline Abrantes; SOUSA, Joana Dark Andrade de; BATISTA, Beatriz Santos. O PLANEJAMENTO COMO INSTRUMENTALIZAÇÃO DA PRÁTICA PEDAGÓGICA NO ENSINO SUPERIOR. In: II Congresso Nacional de Educação, 20I5, Campina Grande - PB. Disponível em 
〈http://www.editorarealize.com.br/revistas/conedu/trabalhos/TRABALHO_EVo45_M DI_SA3_ID7846_08092015205803.pdf $>$. Acesso em II de dezembro de 2017;

BECKER, Fernando. O que é construtivismo? Revista de Educação AEC, Brasília, v. 2I, n. 83, p. 7-I5, abr./jun. 1992;

. Modelos pedagógicos e modelos epistemológicos. In: ALVES, Elizete Lanzoni et al. Metodologia: Construção de uma Proposta Científica, Curitiba: Camões, 2008;

BRANDOLI, Fernanda. NIEMANN, Flávia de Andrade. Jean Piaget: um aporte teórico para o construtivismo e suas contribuições para o processo de ensino e aprendizagem da Língua Portuguesa e da Matemática. In: IX ANPED SUL - Seminário de Pesquisa em $\begin{array}{llllll}\text { Educação da } & \text { Região } & \text { Sul. } & \text { 2012. } & \text { Disponível } & \mathrm{em}\end{array}$ $\langle$ http://www.ucs.br/etc/conferencias/index.php/anpedsul/9anpedsul/paper/viewFile/77 o/7I >. Acesso em 27 de março de 2018;

BRASIL. Lei no 9.394, de 20 de Dezembro de 1996. Estabelece as diretrizes e bases da educação nacional. Disponível em <http://www.planalto.gov.br/ccivil_03/leis/L9394.htm〉. Acesso em in de dezembro de 2017;

. Lei no 8.906, de 4 de julho de 1994. Dispõe sobre o Estatuto da Advocacia e a

Ordem dos Advogados do Brasil (OAB). Disponível em 〈http://www.planalto.gov.br/ccivil_03/leis/L8906.htm〉. Acesso em I7 de outubro de 2017;

BUREAU INTERNACIONAL DE EDUCAÇÃO DA UNESCO. Glossário de Terminologia Curricular. Brasília: UNESCO-IBE, 2016. (Setor de Educação da Representação da UNESCO no Brasil);

CHAKUR, Cilene Ribeiro de Sá Leite. Construtivismo e construção: conceitos-chave para compreender Piaget. In: A desconstrução do Construtivismo na educação: crenças e equívocos de professores, autores e críticos [online]. São Paulo: Editora UNESP, 2014, p. 1625. Disponível em 〈http://books.scielo.org/id/hf4w9/pdf/chakur-9788568334485-02.pdf〉. Acesso em 27 de fevereiro de 2018;

CONCEIÇÃO, Noslean Silva Duarte da. ENSINO JURÍDICO: UM OLHAR DA PEDAGOGIA SOBRE A PRÁTICA BRASILEIRA. Faculdade de Ciências Jurídicas e de Ciências Sociais, 2014, 52f, Trabalho de Conclusão de Curso - Centro universitário de Brasília, Curso de Direito, Brasília;

DORTA, Greice Cristina da Silva; FRANCO, Sandra Aparecida Pires. A INFLUÊNCIA DO PLANO DE AULA NA PRÁXIS DOCENTE: UMA ABORDAGEM NO ENSINO SUPERIOR. In: II Jornada de Didática e I Seminário de Pesquisa do Cemad, 2013. Disponível <http://www.uel.br/eventos/jornadadidatica/pages/arquivos/II\%20Jornada\%20de\%2oDi datica\%20e\%20I\%20Seminario\%20de\%20Pesquisa\%20do\%20CEMAD\%20\%20Docencia\%20na\%2oeducacao\%20Superior\%20caminhos\%2opara\%20uma\%2opraxis\%20 
transformadora/A\%20INFLUENCIA\%20DO\%20PLANO\%20DE\%20AULA\%20NA\%20 PRAXIS\%2oDOCENTE.pdf $>$. Acesso em 02 de março de 2018;

FERREIRA, Heron Conrado do Carmo. et al. PLANEJAMENTO ESTRATÉGICO, FERRAMENTA INDISPENSÁVEL PARA GESTÃO DE INSTITUIÇÕES DE ENSINO SUPERIOR IES PRIVADAS. In: III Simpósio de Excelência em Gestão e Tecnologia, 2006, Resende - RJ. Disponível em $\langle$ https://www.aedb.br/seget/arquivos/artigoso6/440_Artigo_Seget_Heron_II.pdf 〉. Acesso em II de dezembro de 2017;

FGV - Núcleo de Projetos. Exame de Ordem em Números. Volume III, abril 2016. Disponível em <http://fgvprojetos.fgv.br/sites/fgvprojetos.fgv.br/files/oab_3_edicao_v4_web_espelhado. pdf $>$. Acesso em I4 de março de 2018;

FREIRE, Paulo; SHOR, Ira. Medo e ousadia: o cotidiano do professor. 5. ed. Rio de Janeiro: Paz e Terra, 1986;

FREIRE, Paulo. Pedagogia do Oprimido. 63. ed. Rio de Janeiro: Paz e Terra, 2017;

GIESELER, Maurício. Reprovação no XXIII Exame de Ordem foi de 82,93\%. Io out 2017. Disponível em <http://blogexamedeordem.com.br/reprovacao-no-xxiii-exame-deordem/>. Acesso em I4 de março de 2018;

Estatísticas do XXIV Exame de Ordem: 29.910 candidatos aprovados. 7 Mar. 2018. Disponível em <http://blogexamedeordem.com.br/estatisticas-do-xxiv-exame-deordem-29-910-candidatos-aprovados/>. Acesso em I4 de março de 2018;

IBCCRIM. A crise no ensino jurídico. Boletim - 186, Maio de 2008. Disponível em 〈https://arquivo.ibccrim.org.br/boletim_editorial/222-186-Maio-2008〉. Acesso em i6 de maço de 20I8;

LIBÂNEO, José Carlos. Organização e gestão escolar: teoria e prática. Goiânia: Alternativa, 1993;

LIBANIO, João Batista. Introdução à vida intelectual. São Paulo: Loyola, 2ooı;

MACHADO, Ana Maria Ortiz. ENSINO JURÍDICO: APRENDER PARA ENSINAR, ENSINAR PARA APRENDER. Faculdade de Educação, 2006, Io4f, Dissertação (Mestrado) - Pontifícia Universidade Católica do Rio Grande do Sul, Programa de Pós Graduação em Educação, Porto Alegre;

MARCHESE, Fabrizio. A CRISE DO ENSINO JURÍDICO NO BRASIL E AS POSSÍVEIS CONTRIBUIÇÕES DA EDUCAÇÃO GERAL. Faculdade de Educação, 2006, 259f, Dissertação (Mestrado) - Universidade Estadual de Campinas, Programa de PósGraduação em Educação, Campinas; 
MERCADO, Luis Paulo Leopoldo. Metodologias de ensino com tecnologias da informação e comunicação no ensino jurídico. Avaliação, Campinas; Sorocaba, SP, v. 21, n. I, p. 263-299, mar. 2016. Disponível em <http://www.scielo.br/scielo.php?script=sci_arttext\&pid=SI4I440772016000100263\&lng=en\& $\mathrm{nrm}=$ iso\&tlng=pt $>$. Acesso em 27 de fevereiro de 2018;

MIGALHAS. OAB/PR aprova moção para suspender novos cursos de Direito por to anos. 5 fev. 2018. Disponível em <http://www.migalhas.com.br/Quentes/17,MI273708,21048$\mathrm{OABPR}+$ aprova+mocao+para+suspender+novos+cursos+de+Direito+por+Io+anos $>$. Acesso em II de março de 20I8;

MINISTÉRIO DA EDUCAÇÃO. RESOLUÇÃO CNE/CES $\mathrm{N}^{\circ}$ 9, DE 29 DE SETEMBRO DE 2004. Institui as Diretrizes Curriculares Nacionais do Curso de Graduação em Direito e dá outras providências. Diário Oficial da União, Brasília-DF, i out 2004. Disponível em 〈http://portal.mec.gov.br/cne/arquivos/pdf/rceso9_04.pdf 〉. Acesso em 17 de outubro de 2017;

PIMENTA, Guilherme; COURA, Kalleo. Formado em Direito? Veja 23 carreiras possíveis. 03 out. 2016. Disponível em <https://jota.info/carreira/formado-em-direito-veja-23carreiras-possiveis-para-voce-03102016>. Acesso em I7 de outubro de 2017;

PORTAL EDUCAÇÃO. Planejamento do Ensino Superior: O Projeto Pedagógico. Disponível em <https://www.portaleducacao.com.br/conteudo/artigos/esporte/planejamento-do-ensinosuperior-o-projeto-pedagogico/4248I $>$. Acesso em in de dezembro de 2017;

SILVA, Maria Caroline Carneiro. et al. CONTRIBUÇÃO DO PLANO DE DESENVOLVIMENTO INSTITUCIONAL COMO FERRAMENTA DE PLANEJAMENTO ESTRATÉGICO NA GESTÃO DE UMA INSTITUIÇÃO PRIVADA DE ENSINO SUPERIOR DO RECIFE. Revista GUAL, Florianópolis, v. 7, n. 3, p. 77-92, set. 2014;

SANCHIS, Isabelle de Paiva; MAHFOUD, Miguel. CONSTRUTIVISMO: DESDOBRAMENTOS TEÓRICOS E NO CAMPO DA EDUCAÇÃO. Revista Eletrônica de Educação, v. 4, n. I, maio. 2oro. Disponível em $\langle$ http://www.reveduc.ufscar.br/index.php/reveduc/article/view/r2o/86〉. Acesso em $27 \mathrm{de}$ fevereiro de 2018; 